\title{
BIO-MEDICAL APPLICATIONS OF CHITOSAN LINKED PLANT
} NANOPOLYMER

\section{SHLINI P*, MOHAN N AND MULE S \\ *Department of Biochemistry, Mount Carmel College, Autonomous, Palace Road Bengaluru- 560052, Karnataka, India \\ *Corresponding Author: E-Mail: shlinip1@gmail.com \\ Received 234 ${ }^{\text {th }}$ Jan. 2020; Revised 26 ${ }^{\text {th }}$ Feb. 2020; Accepted 31 ${ }^{\text {st }}$ March 2020; Available online $1^{\text {st }}$ Sept. 2020 \\ https://doi.org/10.31032/IJBPAS/2020/9.9.5182}

\begin{abstract}
There has been a remarkable growth of research and applications in the field of nanoscience and nanotechnology. The plant mediated nanomaterial has drawn more attention due to its vast application in various fields because of their physico-chemical properties and also for its simple, cost-effective, eco-friendly and relatively reproducible approach. A considerable research interest in the area of nanotechnology has been witnessed using chitosan nanoparticles as they have emerged as one of the most exciting tools due to their increased surface-volume ratio and are of great interest for nanomedicine, biomedical engineering and development of new therapeutic drug release systems with improved bioavailability, increased specificity and sensitivity, and reduced pharmacological toxicity. The nanopolymer was synthesised using ionic gelation technique and was characterized using UV spectrophotometer and FTIR. The optical density at of the broad peak of Chitosan-jasmine nanopolymer was found at 3.5242. The FTIR results recorded the absorption peaks at 2112 $\mathrm{cm}^{-1}, 1636 \mathrm{~cm}^{-1}$ and $3327 \mathrm{~cm}^{-1}$ which represented the $\mathrm{C}-\mathrm{H}$ stretch, $\mathrm{C}=\mathrm{C}$ stretch and $\mathrm{O}-\mathrm{H}$ bond stretching respectively. Thus, there was a stretching from higher wavelength region to lower wavelength region demonstrating the interaction of tripolyphosphate with chitosan and biomolecules by reduced hydrogen bonding. The present study was designed to determine the cytoprotective and mosquito breeding repellency of Chitosan-jasmine nanopolymer. Altogether, the results of our study lend pharmacological credence to the bio-medical
\end{abstract}


applications, ethno medical use of this plant in traditional system of medicine and as a promising mosquito breeding repellent in the near future. The present research aimed at synthesizing and characterizing a novel chitosan linked plant nanoparticle for nanomedicine, biomedical engineering, industrial and pharmaceutical applications using potent plant source.

Keywords: Chitosan nanopolymer, Jasminum sambac, FTIR, Cytoprotection, Mosquito breeding repellence

\section{INTRODUCTION}

Over the last few years, already been investigated by the nanotechnology and polymers together researchers with the presence of active have captivated a tremendous interest in phytochemicals $[\mathbf{4 , 5}, \mathbf{6}]$. Jasminum sambac many areas including pharmaceutical industry and therapeutic innovation among others. Nanopolymers efficaciously carry proteins, drugs and DNA to targeted cells and organs. Their nanometer-size promotes effective permeation through cell membranes and stability in the blood stream [1]. Green synthesis offers great progress over the other methods as its simple, single step, cost-effective, ecofriendly and relatively reproducible that often results in more stable materials [2].

The world's second most abundant biopolymer- chitosan is a cationic polysaccharide which is obtained by partial deacetylation of chitin and synthesised by Ionic gelation technique has recently gained a considerable attention in pharmaceutical, tissue engineering, biosensing and biomedical research due to its several advantages [3].

The chemical, toxicological and pharmacological features of plants have belongs to the family 'oleaceae', which is one of the altimes fragrant flowers cultivated by humans and are known to be the native of subtropical regions [7]. One of the most widely spread plants from the Lauraceae family is Laurus nobilis, which is additionally known as 'Bay' or 'laurel leaves'. It is a native plant in the Southern Mediterranean area [8].

Bougainvillea is outspread throughout the world and they are perennial bloomers. The Plant List has relatively 18 species, amongst which $B$. glabra is found in India [9]. In this research, three different plant sources are considered and based on the comparative analysis of these plant sources, a potent plant source is determined for our further work.

The erythrocyte serves as a master regulator of metabolism and life by unremittingly delivering oxygen to the cells and tissues of an organism in developmental, physiological and regenerative contexts. 
Under oxidative stress, hemolysis of RBCs takes place due to the action of ROS. Oxidative stress leads to haemoglobin oxidation resulting in the onset of heme degradation products on RBC membrane and reduced ability to deform its shape [10].

Mosquito control is a vital public health practice throughout the world. The most practicable way for reducing incidences of mosquito borne diseases is by controlling mosquito immatures in their breeding sites. In the view of the above, the present study aimed on the fabrication and characterisation of bio-molecules crosslinked with chitosan nanoparticles using the potent plant sources and to investigate the cytoprotective action of Chitosan nanopolymer with the methanolic extract of J.sambac against membrane damage in $\mathrm{RBC}$ and also to determine its efficacy as a mosquito breeding repellent.

\section{MATERIALS AND METHODS}

Chemicals: $\quad 70 \%$ methanol, Dil. $\mathrm{HCl}$, aq. $\mathrm{NaOH}$, Chloroform, con. $\mathrm{H}_{2} \mathrm{SO}_{4}$, acetic acid, ethyl acetate, 3\% Boric acid \& 10\% oxalic acid spray, acetic acid, 10\% Alluminium chloride, 1M Phosphoric acid, 1M Gallic acid, 7.5\% Sodium sulphate, $10 \%$ Folin Ciocalteau's reagent, $0.1 \mathrm{~N}$ Sodium hydroxide, $70 \%$ chilled ethanol, nbutanol, 0.1N Hydrochloric acid, Methyl red indicator, $2 \%$ Acetic acid were of analytical grade obtained from Fischer Scientific. TLC Silica gel plate was of silica gel $\mathrm{GF}_{254}$, Merck. 1\% Ferric chloride, Sodium carbonate, Dragandroff's reagent was obtained from Laboratory reagents. Quercitin, Gallic acid, 0.5\% Chitosan, 0.5\% Sodium-tri-phosphate (TPP), Salmon milt DNA $(200 \mu \mathrm{g} / \mathrm{mL})$ were analytical grade chemicals from HiMedia, Karnataka. 85\% aqueous phosphoric acid of $\mathrm{p}^{\mathrm{H}} 1.76$ and $10 \%$ aqueous acetonitrile was obtained from Lab scan, Analytical Science, Bangalore. 1M Phosphate Buffer Saline (PBS) was obtained from SD Fine Chem Ltd.

Plant Source: The tender leaves of Jasmine (Jasminum sambac) and fresh bracts of Bouganvillea (B. buttiana) were collected from Lalbagh Botanical Garden, Bangalore. The dried Bay leaves (Laurus nobilis) were commercially obtained from K.R. market of Bangalore. The selection of plant sources was done by convenience sampling technique as it's incredibly prompt, simple approach, uncomplicated and economical.

Preparation of plant extract: The plant extracts were prepared from the leaves of Jasminum sambac, bracts of $B$. buttiana and from dried leaves of Laurus nobilis. The dust particles on their surface were washed and cleaned under tap water, sun dried for 10 days and made into fine 
powder. The coarse powder of J.sambac [10 g (w/v)], B. buttiana [10 g (w/v)] and Laurus nobilis $[10 \mathrm{~g}(\mathrm{w} / \mathrm{v})]$ were extracted with $150 \mathrm{~mL}$ of hydro-methanol (30:70) using soxhlet apparatus for $12 \mathrm{~h}$ at $64^{\circ} \mathrm{C}$ not exceeding the boiling point of the solvents. The extracts were then concentrated to dryness and used for further experimental analysis.

\section{Phytochemical analysis:}

A. Qualitative analysis: Test for Alkaloids, Flavonoids, Phenolics and Tannins using $1 \mathrm{~mL}$ extract was carried out allowing it to react with the specific reagents as described by the standard protocols [11].

B. Quantitative analysis of Phenolics, Flavonoids and Alkaloids: The respective concentration of different plant extracts were used to quantitatively test for Phenolics, Flavonoids and Alkaloids as described by the standard quantitative protocols $[12,13,14]$.

Analysis by Thin Layer

Chromatography : TLC was performed on a silica gel plate (silica gel $\mathrm{GF}_{254}$, Merck) 2- $5 \mu \mathrm{L}$ of different plant extracts was deposited to the origins of TLC plates, $2 \mathrm{~cm}$ above its bottom with the help of capillary tubes. The plates were then kept in TLC glass chamber (solvent saturated) and mobile phase was allowed to move through adsorbent phase up to $34^{\text {th }}$ of the plate. TLC was performed for alkaloids, flavanoids, phenolics and tannins using the different solvent systems- Alkaloids: Ethyl acetate: Chloroform: water (5:3:1); Flavonoids: n-Butanol: ethyl acetate: water (5:10:15); Phenolics: methanol: water (6:3) and Tannins: chloroform: water (6:4).

Purification by HPLC : The HPLC analysis was performed using an Agilent 1200 series HPLC (Agilent Technologies Inc., Chemetrix, South Africa), equipped with a binary pump and fitted with an AscentisTM C18 column (Supelco; $25 \mathrm{~cm}$ x 4.6.mm x $5 \mu \mathrm{m}$ particle size). A $5 \mu \mathrm{L}$ J.sambac leaves extract volume was analysed throughout. The diode array detector was used for quantification at 200 nm. The mobile phase consisted of $85 \%$ aqueous phosphoric acid (Solvent $\mathrm{A} ; \mathrm{pH}$ 1.76) and $10 \%$ aqueous acetonitrile (Solvent B, Lab scan, Analytical Science, Poland) at a flow rate of $1.5 \mathrm{~mL} / \mathrm{min}$. A linear gradient was applied from $0-70 \%$ Solvent B in 20 min.

\section{Synthesis of Nanopolymer:}

a. Preparation of plant extract: The plant extract was prepared as explained in the previous section. The extract was then concentrated to dryness and used for further analysis. 
b. Synthesis of chitosan nanoparticles: The ionicgelation method was employed for the synthesis of chitosan nanoparticle using Sodium tripolyphosphate (TPP) as crosslinking agent. About 1\%(w/v) of the J.sambac extract was mixed with $0.5 \%(\mathrm{w} / \mathrm{v})$ of TPP and the solution was added drop wise into the chitosan solution containing $0.5 \%(\mathrm{w} / \mathrm{v})$ chitosan and $1 \%(\mathrm{v} / \mathrm{v})$ acetic acid under gentle magnetic stirring of REMI 2-MLH.. The solution was incubated for 20 mins and used for characterization [15].

\section{Characterisation of nanopolymers:}

a) UV spectrophotometer: The interaction of Chitosan and the target compound in the nanopolymer suspension was checked by measuring in UV-Vis range. The absorbance spectrum of the nanopolymer suspension was recorded quickly after the synthesis was done and a reference of deionized water was recorded prior to the actual sample analysis. To check the stability of nanopolymer, the absorption spectrum was recorded to pure chitosan, Jasmine extract, TPP, TPP - Jasmine extract,
Chitosan-TPP, Chitosan-Jasmine extract and Chitosan-TPP- Jasmine extract. The spectrophotometer used was a Chemito UV Scan 2600 (Thermo Fisher) and the software was Spectrum ${ }^{\mathrm{TM}}$ Version 6.87. Absorbance spectra were recorded over an extend of $220-400 \mathrm{~nm}$. Wavelength of peak absorbance and $\lambda \max$ was also calculated.

b) FTIR spectral analysis: The biomolecules stacked chitosan nanoparticles were freeze dried and the powdered test was used for FTIR spectroscopy studies. The dried experimental test was specifically put on the $\mathrm{KBr}$ crystals and was compressed to make pellets. Then, FTIR examination of chitosan nanoparticles sample was performed with a2 technologies portable attenuated total reflectance (ATR) Fourier transform infrared spectroscopy (ATR-FTIR). Sample spectra were recorded within the range of $4000 \mathrm{~cm}^{-1}$ to $400 \mathrm{~cm}^{-1}$ with a resolution of $4 \mathrm{~cm}$ in the absorbance mode for 10 scans at room temperature. FTIR spectra of chitosan nanoparticles were obtained by placing $1 \mathrm{mg}$ of test on the sensor of the instrument and 
spectrum was then compared with the spectrum of Chitosan standard.

\section{In vitro Erythrocyte Cytoprotection} assay: On a microscopic glass slide, a small drop of freshly drawn blood sample was taken. It was diluted 5 to 7 folds with PBS, mixed gently and viewed under high power of Phase contrast microscope (Olympus-CKX41). It was treated with $\mathrm{FeSO}_{4}{ }^{-}$a damaging agent and the effects were noted. The cells were then subjected to co-treatment with Chitosan-TPP-Plant extract - a potent nanopolymer and the subsequent effects were recorded. The cytoprotective action of each was noted based on the time taken for the disappearance of erythrocyte membrane damage.

Each of the four extracts was then used, both before and after treatment with the oxidant and the cytoprotective action of each was noted. In the first set of experiment, RBCs are subjected to damage induced by ferrous sulphate and then cotreated with the extracts. In the next set of experiment, the erythrocytes were pretreated with the extracts and then treated with the oxidant. The cytoprotective potential of each extract was assessed based on the time taken for the appearance of erythrocyte membrane damage in each case.

\section{Determination of potential inhibitor of mosquito breeding activity by Chitosan-} Jasmine nanopolymer: $500 \mathrm{~mL}$ of stagnant water was collected from the house garden in a container. It was then divided into two parts as one being control and the other as test. To the test sample, $10 \mathrm{~mL}$ of $1 \%$ Chitosan-Jasmine nanopolymer was added and was kept under observation for a week. Later, the test was compared with the control.

\section{RESULTS AND DISCUSSION}

Phytochemical analysis: The preliminary phytochemical screening of methanolic extracts of Jasmine, Bay leaf and Bougainvillea was performed which determined the presence of various phytoactive constituents. Methanol being a universal solvent has the ability to attract almost all bioactive compounds from plants because of the presence of polar group $(\mathrm{OH})$ and non-polar group $(\mathrm{CH})$. The result of phytochemical screening of these methanolic plant extracts has been tabulated in Table 1.

As illustrated in the Table 1, Bay leaf showed the presence of higher quantity of alkaloids than flavanones and terpenoids. Jasmine, on the other hand confirmed the presence of highest amounts of alkaloids, terpenoids and flavones respectively. Furthermore, Bougainvillea showed the presence of only alkaloids and flavones in a 
relatively less amounts in comparison to Jasmine and Bay leaf.

The earlier phytochemical investigations of J.sambac with water, ethyl acetate and hexane solvents has revealed the presence of alkaloids, steroids/triterpenes, saponins, tannins, phenolics, flavonoids and glycosides respectively [16]. The species of Bougainvillea has revealed the presence of alkaloids, steroids, glycosides, flavonoids in chloroform extract and in ethyl acetate extract [17]. Also, L.nobilis with various solvent extracts has confirmed the presence of tannins, alkaloids, reducing compounds, saponins, anthracenosides, alkaloids fatty acids, volatile oil, free quinines, polyuronides and sterols/steroids [18]. Thus, the previous study on phytochemical screening of these plant extracts has correlated with our qualitative phytochemical analysis of L.nobilis, J.sambac, B. buttiana.

(A) Quantitative Analysis of Total Phenols:

These findings illustrated that the total phenolic content of crude ethanolic extact of jasmine was found to be $2.567 \mathrm{mg} / \mathrm{g}$ of tannic acid equivalents, which was higher than that of crude ethanolic extracts of Bougainvillea and Bay leaf. Phenolic compounds are a class of antioxidant agents which acts as free radical terminators [19].
The total phenolic content in plant extracts relies on the polarity of the solvent used for extraction. The degree of solubility of phenols in polar solvent determines the concentration of phenolic compounds in the extract [20]. The content of phenolics was expressed in terms of tannic acid equivalents, $\mathrm{mg}$ of $\mathrm{TA} / \mathrm{g}$ of extract (Table 2).

(B) Determination of Total Flavonoid Content:

The total flavonoid content of crude ethanolic extact of jasmine was found to be $1.103 \mathrm{mg} / \mathrm{g}$ of Quercetin equivalents, which was higher than that of crude ethanolic extracts of Bougainvillea and Bay leaf. Flavonoids along with flavones, flavanols and condensed tannins exhibit antioxidant activity which depends on the presence of free $\mathrm{OH}$ groups, especially 3-OH. Plant flavonoids possess antioxidant activity in vitro and act as antioxidants in vivo [21]. The content of flavonoids was expressed in terms of quercetin equivalents, mg of $\mathrm{QE} / \mathrm{g}$ of extract (Table 3).

(C) Quantitative Analysis of Total Alkaloids (Plummer DT, 1990):

A rapid assay was followed to determine the total alkaloids using 
back titration with an acid employing potentiometric determination of endpoint. The alkaloids concentration was determined by the amino groups of alkaloids neutralising the $\mathrm{HCl}$ concentration. The quantitative analysis of alkaloids in the leaves of screened plants is represented in Table 4. The range of total alkaloids content was found to vary from $0.136 \pm 0.009 \mathrm{~g} \% \mathrm{w} / \mathrm{v}$ dry weights to $0.704 \pm 1.3 \mathrm{~g} \% \mathrm{w} / \mathrm{v}$ dry weights.

The highest concentration of alkaloid was found to be $0.704 \pm 1.35 \mathrm{~g} \% \mathrm{w} / \mathrm{v}$ in butanolic extract of jasmine, followed by bougainvillea and least in bay leaf.

\section{(D) Analysis by Thin Layer}

\section{Chromatography:}

TLC profiling is used to monitor the reaction progression, identification of the components and the determination of the purity of the mixture. This analytical tool is used because of its simplicity, speed of separation, cost effectiveness and high sensitivity [22]. The potent plant biomolecules were further used for development of the different drugs in future or in miscellaneous applications.

As illustrated in the Table 5, Jasmine and Bay leaf confirmed the presence of alkaloids by the appearance of reddish brown spots on spraying Dragendroff's reagent. Phenolics and flavanoids were confirmed in Jasmine, Bay leaf and Bougainvillea by the appearance of grey colour upon $\mathrm{FeCl}_{3}$ spray and by the green fluorescence after being sprayed by 3\% boric acid and $10 \%$ oxalic acid solution. And, Bougainvillea confirmed the presence of tannins by the appearance of brownish grey colour spot respectively under the view of UV trans-illuminator.

\section{(E) TLC Profiling}

TLC profiling of J.sambac revealed several phytochemicals such as Alkaloids, anthraquinones, coumarins, essential oils, flavanoids, antioxidants, cardiac glycosides, phenolics, saponins and tannins [23]. By the TLC profiling, the potent bioactive compounds from the plant extracts were detected to be in the order of Jasmine $>$ Bay leaf $>$ Bougainvillea based on their respective $\mathrm{Rf}$ values.

As per our preliminary analysis and their ethnobotanical significance, the comparative study of all the three plant sources revealed that Jasmine leaves was more potent plant source than Bay leaf and Bougainvillea due to the fact that it signified the 
presence of various bioactive compounds in different solvent systems under phytochemical screening. And, thus the extract of Jasmine leaves was observed to be more promising in terms of the bioactivities as well as the profound applications that it possesses. Hence was subsequently considered in our further investigation (Figure $1 \mathbf{a}, \mathbf{b}$ ).

\section{(F) Purification by HPLC:}

The standard Caffeic acid with the concentration $(0.1 \mathrm{mg} / \mathrm{mL})$ was run using RP-HPLC C-18 column with an isocratic mode of elution by $85 \%$ aqueous phosphoric acid $(\mathrm{pH}-1.76)$ and aqueous $10 \%$ acetonitrile as the mobile phase, where diode array was used as detector for the quantification of alkaloids at $240 \mathrm{~nm}$.

The Figure 2(a) illustrated two peaks at a time interval of $2.103 \mathrm{~min}$ and 3.240 min respectively. Resolution of the baseline of analytes and IS was achieved with a C18 column, without any amine modifiers in the mobile phase. The standard retention time and other factors pertained to our studies has been tabulated in the Table 6.

The HPLC analysis of methanolic extract of J.sambac determined the quantification of alkaloids at specific time intervals. The sample's chromatogram revealed two most important peaks at $2.1667 \mathrm{~min}$ and $2.6833 \mathrm{~min}$, and two minor peaks was additionally revealed at $3.3333 \mathrm{~min}$ and $4.4667 \mathrm{~min}$ respectively. On correlating the RP-HPLC chromatograms of the sample with the standard, there was a similarity in two peaks of 2.103 min of standard with $2.1667 \mathrm{~min}$ of sample and $3.240 \mathrm{~min}$ of standard with $3.3333 \mathrm{~min}$ of the sample, which determined quantitatively the presence of alkaloids in the methanolic extract of J.sambac leaves.

The quantitative analysis of alkaloids retention time has been illustrated in the Table 7, which exhibited good linearity between concentration and peak area. The amount of alkaloids present in the J.sambac methanolic extract of leaves was found to be $142 \mu \mathrm{g} / 10 \mathrm{mg}$. It was assumed that the two peaks with retention time 2.6833 min and 3.3333 min were codeine and caffeine respectively.

\section{(G) Characterisation of nanopolymers:}

An opalescent solution of Chitosanjasmine nanopolymer was initially characterised by UV-Vis spectrophotometer to check the validity and stabilty of prepared nanopolymer. As a preliminary aspect, 
Figure 3 illustrated that all the optical density coincided at a specific wavelength of $290 \mathrm{~nm}$ which revealed the nanopolymer formation. The maximum absorption peak for Chitosan-jasmine nanopolymer was found at 3.5242 OD. Broad absorption bands of chitosan nanoparticle were contemplated at $200-322 \mathrm{~nm}$ in UVVisible spectrophotometer analysis [24]. Our current study correlated with his revelation as the broad peak of pure chitosan was also in the range of 280-322nm.

The capability of the ionic gelation process to form biomolecules loaded chitosan nanoparticles was assessed by FTIR for the determination of plant-chitosan interactions. FTIR measurements were performed to identify the possible biomolecules responsible for chitosan nanoparticle formation. The spectral analysis of chitosan nanoparticles and bioactive molecules loaded chitosan nanoparticles were depicted in the Figure 4(a) and Figure 4(b). The IR studies of chitosan nanoparticles (CNPs) revealed the presence of peaks at $3333 \mathrm{~cm}^{-1}, 2111 \mathrm{~cm}^{-1}, 1637 \mathrm{~cm}^{-1}$, $1391 \mathrm{~cm}^{-1}, 1278 \mathrm{~cm}^{-1}, 528 \mathrm{~cm}^{-1}$ and $514 \mathrm{~cm}^{-1}$ while the FTIR spectra of J.sambac plant extract derived chitosan nanoparticles (JSCNPs) revealed strong absorption peaks at $3327 \mathrm{~cm}^{-1}, 2112 \mathrm{~cm}^{-1}, 1636 \mathrm{~cm}^{-1}$, $1279 \mathrm{~cm}^{-1}, 1017 \mathrm{~cm}^{-1}$ and $521 \mathrm{~cm}^{-1}$. The spectra observed at $3327 \mathrm{~cm}^{-1}$ for the synthesized nanoparticle indicated the stretching of $\mathrm{O}-\mathrm{H}$ bonds which further indicated reduced hydrogen bonding. The occurrence of reduced hydrogen bonding in the cross-linked nanoparticle complexes was due to more open structure resulting from cross linking with alkaloid biomolecules of J.sambac as well as TPP. The peaks recorded at $2112 \mathrm{~cm}^{-}$ ${ }^{1}$ represented the $\mathrm{C}-\mathrm{H}$ stretch of the alkanes group. The strong band noticed at $1636 \mathrm{~cm}^{-1}$ indicated the presence of phosphorous groups. This might be due to the tripolyphosphoric group linking of TPP with ammonium group of chitosan. The isolated alkene groups of the $\mathrm{C}=\mathrm{C}$ stretch was found at $1636 \mathrm{~cm}^{-1}$ for the biomolecules loaded chitosan nanoparticle. The absorption spectra observed at 1279 $\mathrm{cm}^{-1}$ indicated the presence of carboxylate group. The $\mathrm{C}-\mathrm{N}$ stretching of aliphatic amines was observed at the peaks of $1017 \mathrm{~cm}^{-1}$ and the aromatic groups were presented with intense peaks at $521 \mathrm{~cm}^{-1}$ for the synthesized nanoparticles. These 
observed peaks were shifted from the higher wave number region to the lower wave number region due to the interaction of the tripolyphosphate molecules binding with chitosan and the plant bioactive molecules. Due to the increase in the bond length, the stretching frequency has decreased and the wave numbers have shifted from higher frequency to lower frequency. Thus, it was found that the inter and intra-molecular actions were enhanced in chitosan nanoparticles due to polyphosphoric groups of sodium polyphosphate interaction with the ammonium groups of chitosan [25].

\section{(H) In vitro Erythrocyte Cytoprotection}

\section{assay:}

The relative in vitro antioxidant and free radical scavenging activities of the Chitosan-Jasmine nanopolymer and ascorbic acid were studied and it was observed that the ChitosanJasmine nanopolymer possessed significant potential to overcome the induced toxicity when compared with ascorbic acid. Crenations were induced by ferrous sulphate in the cell membrane of erythrocytes which caused the loss of its biconcave shape and thereby impaired its deformability. Red Blood Cells
(RBCs) were deformed and squeezed through narrow capillaries. Therefore, decreased deformability was one of the factors that contributed to the elimination of aged or damaged RBCs from the circulation [26]. This process caused an impaired oxygen delivery, which contributed to the pathology of a number of diseases. Damage to erythrocytes was manifested in haemolysis, which was associated with some haemoglobinopathies and deficiencies in a number of erythrocyte antioxidant systems [27]. The proteolysis was also activated by oxidative challenge of erythrocytes which lead to the alteration of the shape and function [28].

Treatment with ascorbic acid and the Chitosan-Jasmine nanopolymer were contemplated to negate the cytotoxic effect of ferrous sulphate and the biconcave shape of RBCs was restored. On pretreatment of RBCs with the Chitosan-Jasmine nanopolymer followed by treatment with the oxidant, it was observed that the Chitosan-Jasmine nanopolymer had the capacity to protect the cells from immediate morphological changes (crenations) induced by ferrous sulphate. The best protection was observed in cells pre-treated with 
Chitosan - Jasmine nanopolymer followed by ascorbic acid. Erythrocytes were highly susceptible to attack by reactive oxygen species because of the high amount of polyunsaturated fatty acid content in their membranes and the metal catalyzed oxidation reactions because of haemoglobin. The oxidation of erythrocytes was a good model for the oxidation of bio membranes. Since, Chitosan-Jasmine nanopolymer reduced the ferrous sulphate-induced alterations in erythrocytes, they were also restored or the morphological changes were reduced that accompanied erythrocyte oxidation. The activity may be due to the presence of different phytochemicals which acted in synergy. Similarly, the RBC's restored it's conformation immediately in Silver linked Chitosan-Jasmine nanopolymer and gradually in Copper linked ChitosanJasmine nanopolymer upon the cotreatment of crenated RBC's. From the above findings, it was illustrated that Chitosan-Jasmine nanopolymer possessed significant in vitro erythrocyte cytoprotectivity (Figure 5).

(I) Inhibition of mosquito breeding activity by Chitosan-Jasmine nanopolymer: The controlling of mosquito breeding potential of J.sambac varies according to the parts of the plant used, solvent choice, season of plant collection, geographical location where the plants were grown, antagonistic nature of mosquito and the application method. The methanolic extract of the J.sambac leaves was screened for the presence of major phytochemical groups. The preliminary phytochemical screening revealed the presence of phenolic compounds, flavonoids, alkaloids and tannins. These phytochemical compounds were the key candidates in the medicinal value of this plant. Later, it was examined for mosquito repellent activity. Chitosan-jasmine nanopolymer exhibited potent repellent activity against mosquito eggs breeding for 5 days exposure. At a minimal dose, extract resulted in $80 \%$ mosquito breeding repellent activity which resulted in the retention of same number of breeding eggs. Also, there was no increase in number of breeding due to the fact that the breeded eggs and few larvae were dead indicating J.sambac has potent mosquitocidal activity. However, the activity may vary on dose dependency and time 
dependency. Benzyl alcohol in

protection is directly proportional to

jasmine oil revealed moderate-high

dose and inversely proportional to

rate of larval mortality [29]. Thus, time (Figure 6 a).

results signified that percentage

Table 1: Qualitative analysis of phytochemicals in the methanolic extracts of Bay leaf, Jasmine and Bougainvillea

\begin{tabular}{|c|c|c|c|c|}
\hline PHYTOCHEMICAL & COLOUR & BAY LEAF & JASMINE & BOUGANVILLAE \\
\hline Alkaloids & Reddish brown & ++ & +++ & + \\
\hline Tannins, phenolics & Violet & - & - & - \\
\hline \multirow{3}{*}{ Flavanoids } & Violet (Anthocyanins) & - & - & - \\
\cline { 2 - 5 } & Yellow (Flavones) & - & + & + \\
\cline { 2 - 5 } & Orange(Flavanones) & + & - & - \\
\hline Terpenoids & Reddish brown & + & ++ & - \\
\hline
\end{tabular}

Note: '+' indicated a positive result and '-' indicated a negative result.

Table 2: Quantitative amount of total phenols in selected plants

\begin{tabular}{|c|c|}
\hline Plant sample & $\begin{array}{c}\text { Amount of total phenol(mg/g Tannic } \\
\text { acid equivalents) }\end{array}$ \\
\hline Jasmine & 2.567 \\
\hline Bougainvillea & 1.962 \\
\hline Bay leaf & 1.395 \\
\hline
\end{tabular}

Table 3: Quantitative amount of total flavonoids in the selected plants

\begin{tabular}{|c|c|}
\hline Plant sample & $\mathrm{mg} / \mathrm{g}$ of QE/g of extract \\
\hline Jasmine & 1.103 \\
\hline Bougainvillea & 0.571 \\
\hline Bay leaf & 0.984 \\
\hline
\end{tabular}

Table 4: Quantitative amount of total alkaloids in selected plants

\begin{tabular}{|c|c|}
\hline Plant sample & $\begin{array}{c}\text { Amount of total alkaloids(g\%w/v) of } \\
\text { dry weight }(\text { mean } \pm \text { SD) }\end{array}$ \\
\hline Jasmine & $\mathbf{0 . 7 0 4} \pm 1.35$ \\
\hline Bougainvillea & $\mathbf{0 . 1 5 0} \pm 0.009$ \\
\hline Bay leaf & $0.136 \pm 0.009$ \\
\hline
\end{tabular}

Table 5: Qualititative confirmatory test for the phytochemicals in the extracts of Jasmine, Bougainvillea and Bay leaf by TLC

\begin{tabular}{|c|c|c|c|c|c|}
\hline Phytochemicals & Solvent System & Confirmatory & Jasmine & Bay Leaf & Bougainvillea \\
\hline Alkaloids & $\begin{array}{c}\text { Ethyl acetate: } \mathrm{CHCl}_{3} \text { : } \\
\mathrm{H}_{2} \mathrm{O} \\
(5: 3: 1)\end{array}$ & $\begin{array}{c}\text { Dragendroff's } \\
\text { Reagent }\end{array}$ & + & + & - \\
\hline Flavonoids & $\begin{array}{c}\text { n-Butanol: Ethyl } \\
\text { acetate: } \mathrm{H}_{2} \mathrm{O} \\
(5: 10: 15)\end{array}$ & $\begin{array}{l}3 \% \text { boric acid }+ \\
10 \% \text { oxalic acid }\end{array}$ & + & + & + \\
\hline Phenolics & $\begin{array}{c}\mathrm{CH}_{3} \mathrm{OH}: \mathrm{H}_{2} \mathrm{O} \\
(6: 3)\end{array}$ & $1 \% \mathrm{FeCl}_{3}$ & + & + & + \\
\hline Tannins & $\begin{array}{c}\mathrm{CHCl}_{3}: \mathrm{H}_{2} \mathrm{O} \\
(6: 4)\end{array}$ & $1 \% \mathrm{FeCl}_{3}$ & - & - & + \\
\hline
\end{tabular}




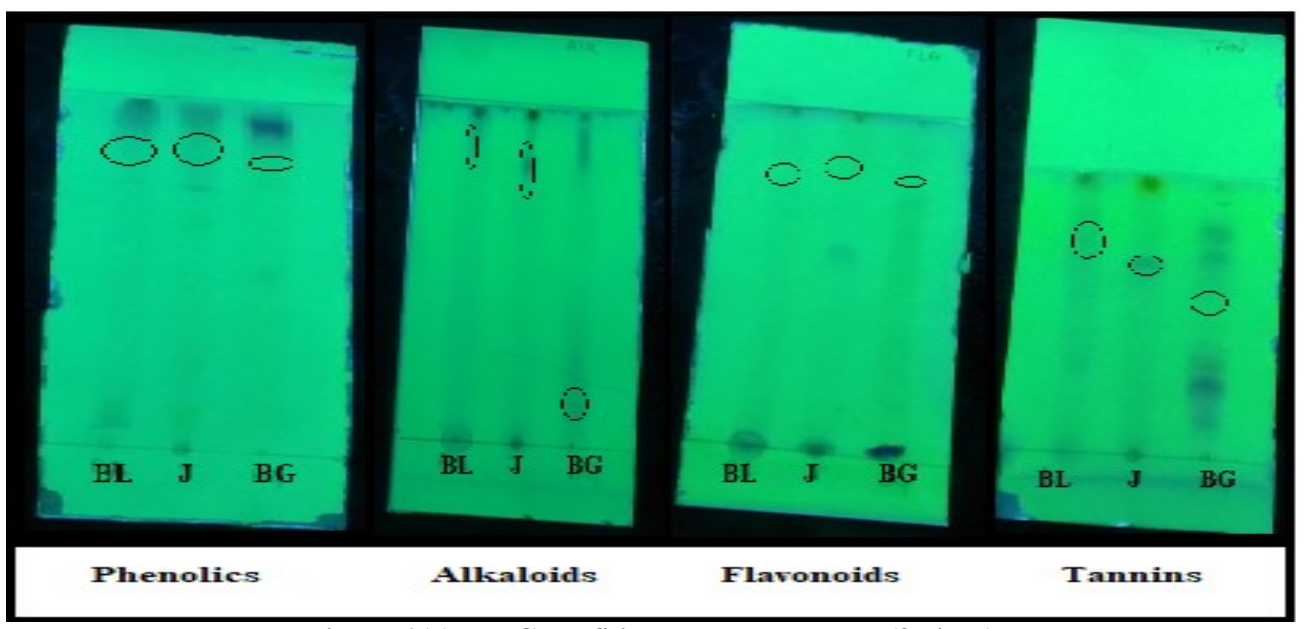

Figure 1(a): TLC profiling under short UV (254nm)

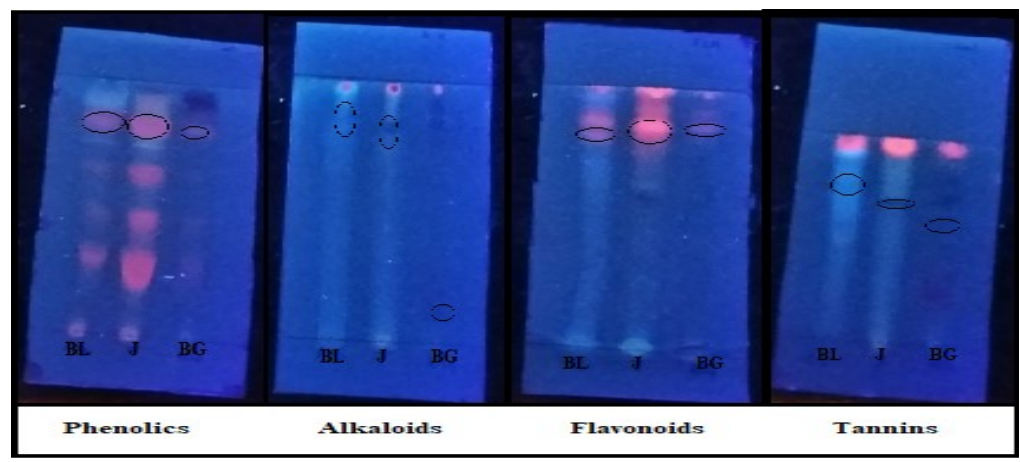

Figure 1(b): TLC profiling under long UV (365nm)

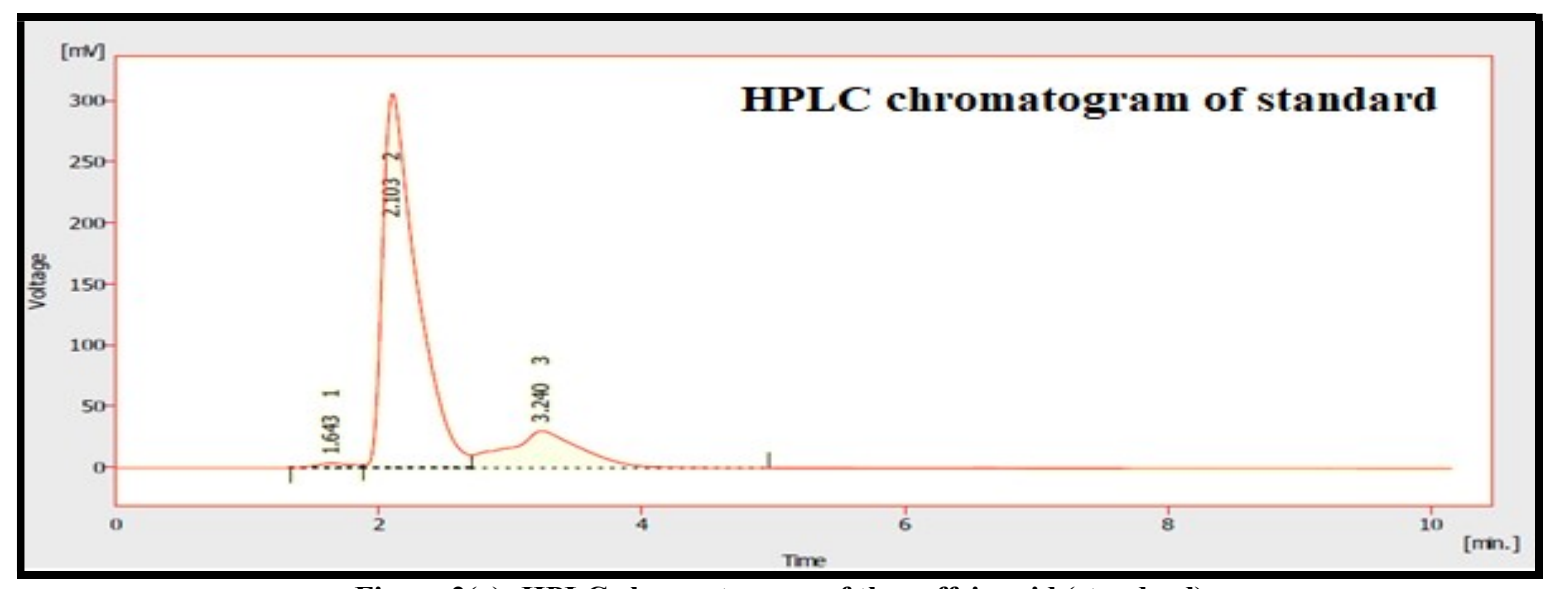

Figure 2(a): HPLC chromatogram of the caffeic acid (standard)

Table 6: Retention time of standard Caffeic acid by HPLC 


\begin{tabular}{|c|c|c|c|r|r|r|}
\hline & $\begin{array}{c}\text { Reten. Time } \\
{[\mathrm{min}]}\end{array}$ & $\begin{array}{c}\text { Area } \\
{[\mathrm{mV} . \mathrm{s}]}\end{array}$ & $\begin{array}{c}\text { Height } \\
{[\mathrm{mV}]}\end{array}$ & $\begin{array}{c}\text { Area } \\
{[\%]}\end{array}$ & $\begin{array}{c}\text { Height } \\
{[\%]}\end{array}$ & \multicolumn{1}{c|}{$\begin{array}{c}\text { W05 } \\
{[\mathrm{min}]}\end{array}$} \\
\hline 1 & 1.643 & 69.185 & 3.651 & 1.0 & 1.1 & 0.37 \\
\hline 2 & 2.103 & 5538.941 & 306.087 & 81.3 & 90.0 & 0.27 \\
\hline 3 & 3.240 & 1201.542 & 30.183 & 17.6 & 8.9 & 0.64 \\
\hline & Total & 6309.668 & 339.921 & 100.0 & 100.0 & \\
\hline
\end{tabular}

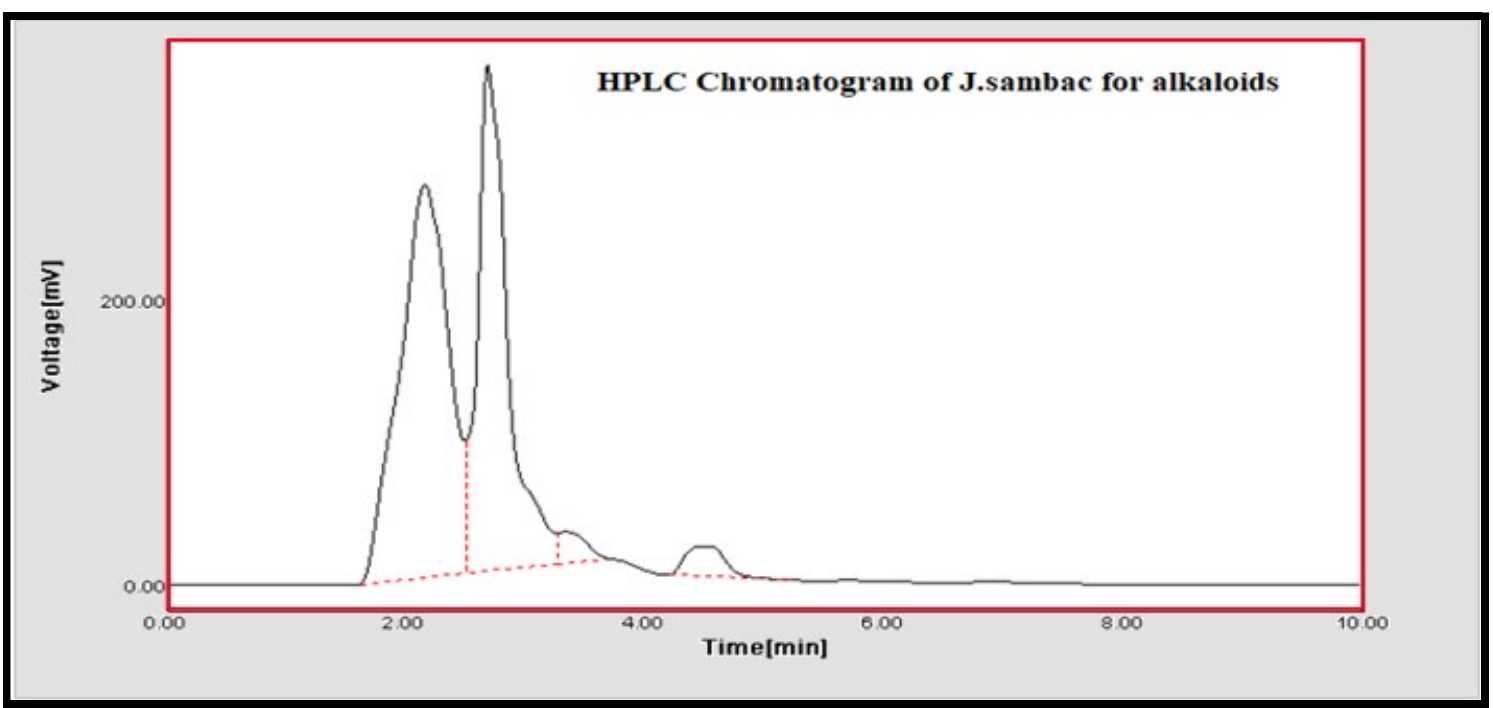

Figure 2(b): Chromatogram of the purification of methanolic extract of Jasmine by HPLC

Table 7: Result table of HPLC purification of methanolic extract of Jasmine by HPLC

\begin{tabular}{|c|c|c|c|}
\hline No. & Retention Time (min) & Area $\left[\mathrm{mV}^{*} \mathbf{s}\right]$ & Height $[\mathrm{mV}]$ \\
\hline 1 & 2.1667 & $\mathbf{7 8 8 6 . 6 6 3 1}$ & $\mathbf{2 7 6 . 9 6 4 6}$ \\
\hline 2 & 2.6833 & 6312.7466 & 355.9515 \\
\hline 3 & 3.3333 & 330.7656 & 21.7028 \\
\hline 4 & 4.4667 & 483.1823 & 20.9117 \\
\hline Total & \multicolumn{1}{|l}{} \\
\hline
\end{tabular}

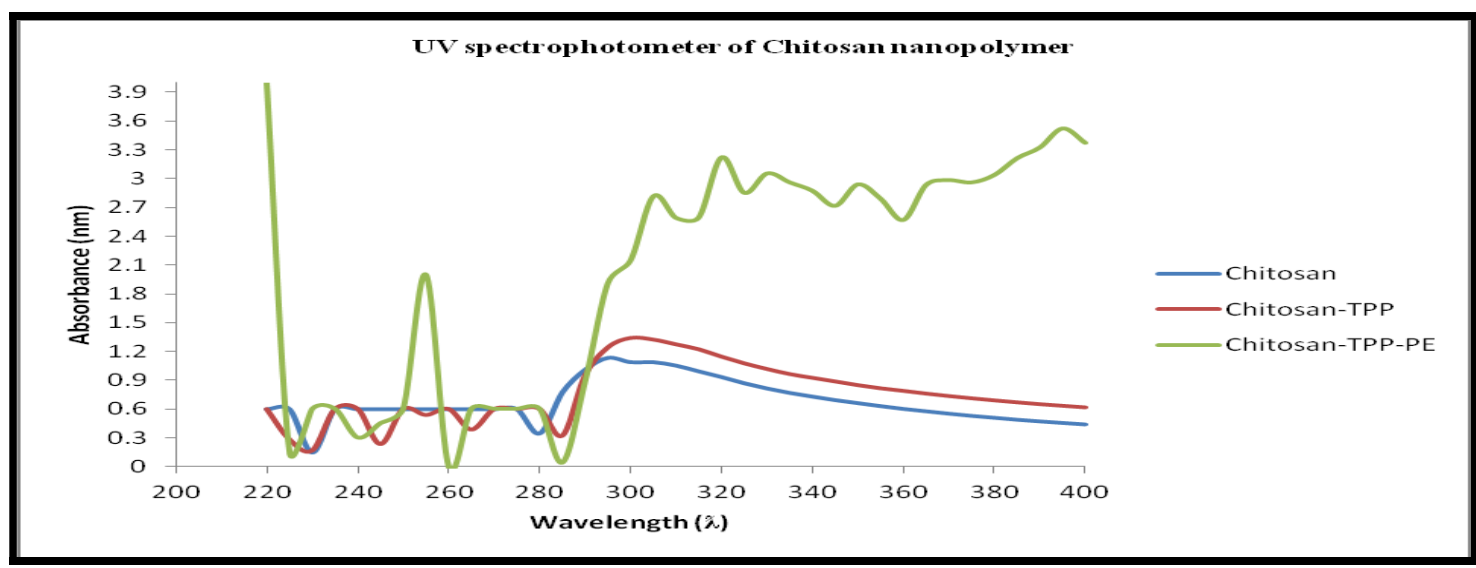

Figure 3: UV-Vis spectrum of pure chitosan(Chi), solution of $0.5 \%$ chitosan and $1 \%$ TPP (Chi- TPP), and solution of $0.5 \%$ chitosan, $1 \%$ TPP and $1 \%$ P.E(Chi-TPP-P.E) 


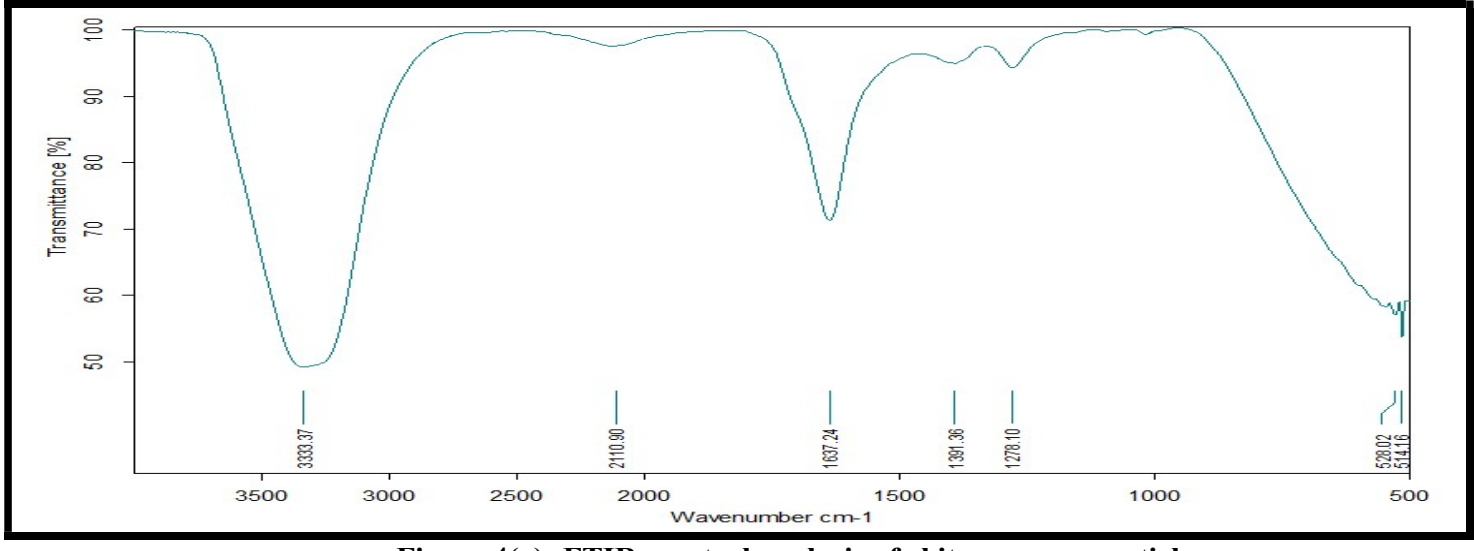

Figure 4(a): FTIR spectral analysis of chitosan nanoparticles

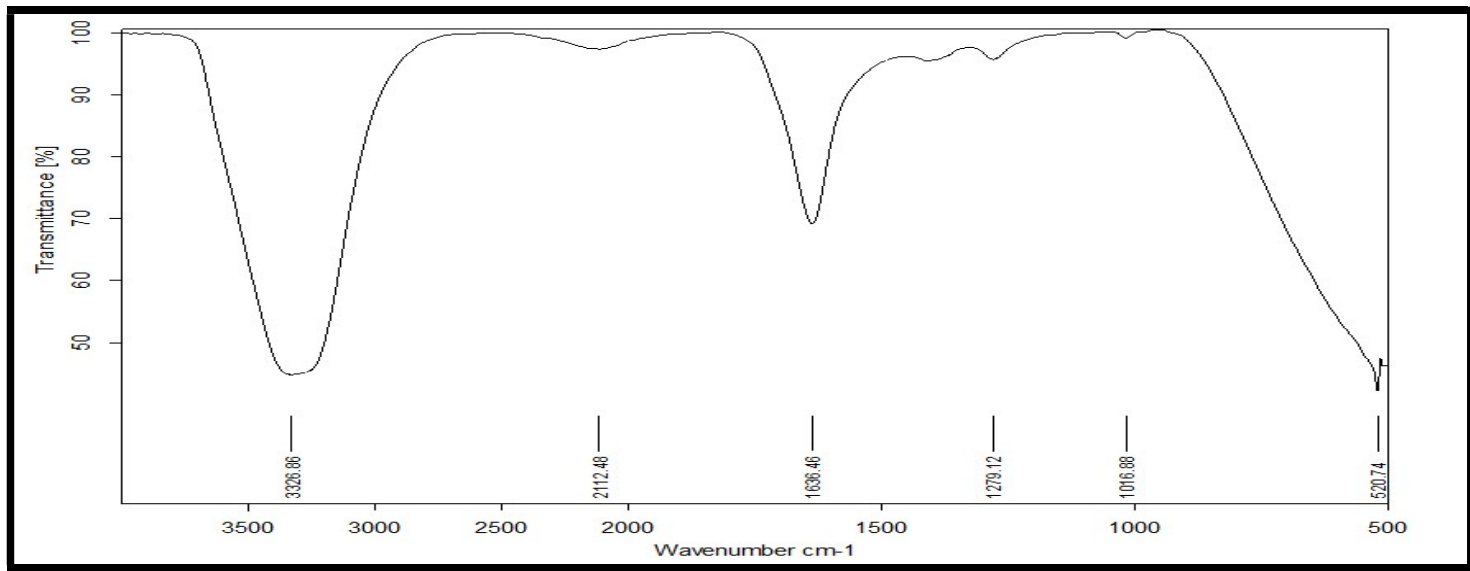

Figure 4(b): FTIR spectral analysis of J.sambac leaf extracts derived phytochemicals Cross-linked chitosan nanopolymer
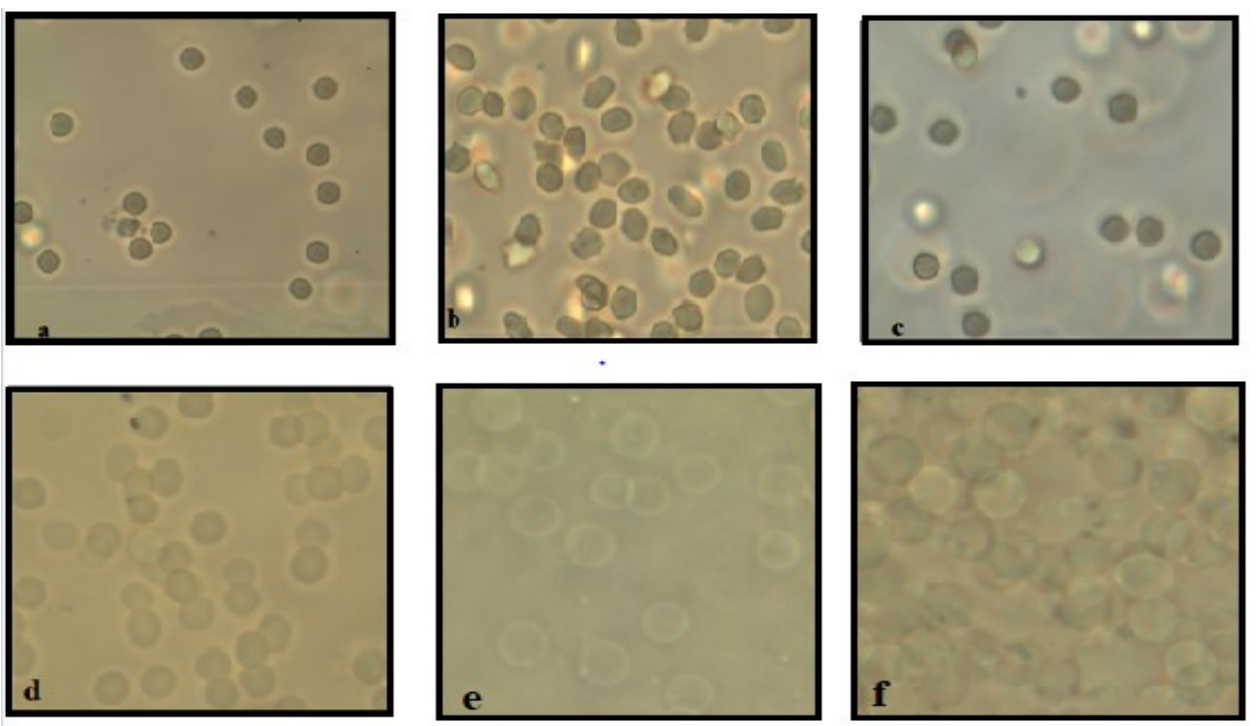

Figure 5: Treatment of erythrocytes with oxidant and antioxidant- (a) Human RBCs diluted with PBS as observed in 40X of phase contrast microscope. (b) Appearance of crenation on treatment with the oxidant-ferrous sulphate. (c) Restoration of crenation on treatment with standard antioxidant-ascorbic acid. (d) Co treatment of crenated cells with Chitosan-Jasmine nanopolymer. (e) Co treatment of crenated cells with Silver-Chitosan-Jasmine nanopolymer.

(f) Co treatment of crenated cells with Copper-Chitosan-Jasmine nanopolymer 

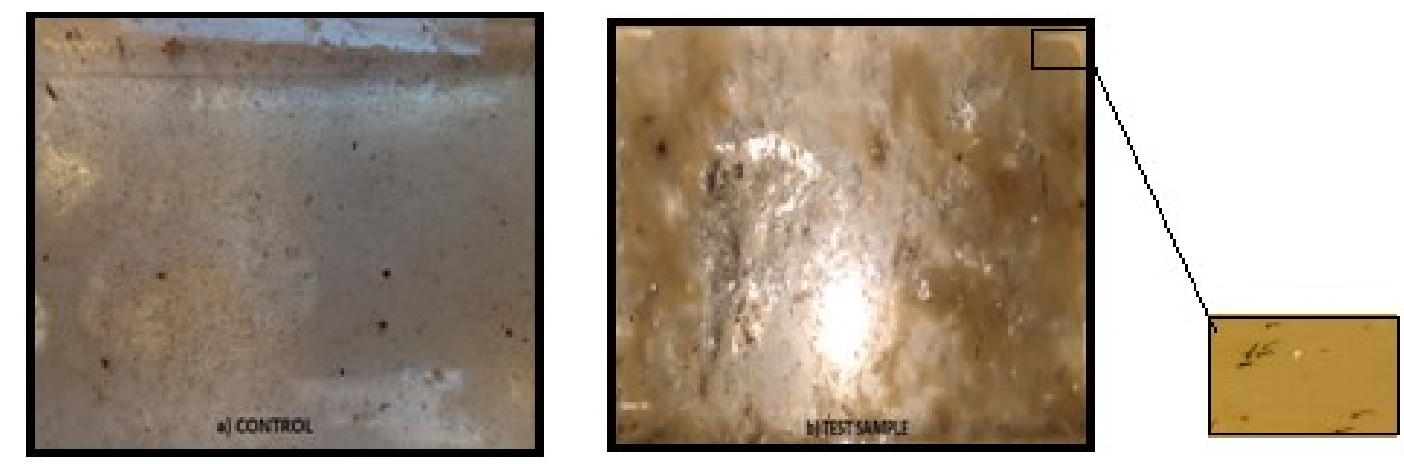

Figure 6: a) Control and b) test sample determining the Chitosan-jasmine nanopolymer as a potent mosquito breeding inhibitor

\section{CONCLUSION}

The present study aimed at the comparative studies on the different plant sources such as Bay leaf, Bougainvillea and Jasmine leaves. The findings implied that Chitosan- jasmine nanoparticles possessed the significant cytoprotective action as it had the ability to restore the crenated RBCs to their biconcave form and also inhibited the further mosquito breeding, thereby proving to be a potent repellent agent. Thus, our current study gives the detailed information about the properties of Chitosan-jasmine nanopolymer, its future applications in pharmaceuticals and its effectiveness as a prototype for larvicidal agents in the mosquito breeding habitats that will obviously work as a new weapon in the arsenal of synthetic drugs and products by its eco-friendly and non-toxic approach.

\section{ACKNOWLEDGEMENT}

The authors would like to express their gratitude to the Department of Chemistry (PG Biochemistry) and the management of Mount Carmel College, Autonomous, Bengaluru for funding this project and offering their facilities for the analysis.

\section{REFERENCES}

[1] Peer D, Karp J.M, Hong S, Farokhzad O.C, Margalit R and Langer R. "Nanocarriers as an emerging platform for cancer therapy". Nat. Nanotechnol. 2, (2007). 761-770.

[2] Mittal, J., Batra, A., Singh, A., \& Sharma, M. M. Phytofabrication of nanoparticles through plant as nanofactories. Advances in Natural Sciences: Nanoscience and Nanotechnology, 5(4) (2014). 043002.

[3] Malesu VK, Sahoo D, Nayak PL. Chitosan sodium alginate nanocomposites blended with cloisite $30 \mathrm{~B}$ as a novel drug delivery system for anticancer drug curcumin. IJABPT 2: (2011) 402411. 
[4] Nathasa Weisdania Sihite , Herla Rusmarilin, Dwi Suryanto and Dewi Restuana Sihombing. Utilization of jasmine flower extract as antimicrobial in tempeh sausage. IOP Conf. Series: Earth and Environmental Science, IOP Publishing, (2018) 10.1088/17551315/205/1/012037

[5] E. Manivannan, R. Kothai, B. Arul, and S. Rajaram "Anti-inflammatory activity of bougainvillea spectabilis linn," Research Journal of Pharmaceutical, Biological and Chemical Sciences, 3( 1): (2012) 642-646.

[6] Farah Haddouchi, Tarik Chaouche, Abdelhafid Benmansour and Hamadi Abderrahmane Lazouni. "Phytochemical study of Thymus fontanesii and Laurus nobilis".Der Pharmacia Lettre, 3(2): (2011). 343350

[7] Swati sabharwal, manisha vats, satish sardana \& sushma aggarwal. "Pharmacognostical, physico and phytochemical evalution of the leaves of jasminum sambac linn. (oleaceae)". International journal of Pharmacy and Pharmcuetical Sciences; 3(4): (2011)237-241

[8] Marzouki H, Piras A, Salah KB, Medini H, Pivetta $\mathrm{T}$, et al.
"Essential oil composition and variability of L.nobilis L. growing in Tunisia, comparison and chemometric investigation of different plant organs" Natural Product Research 23: (2009). 343354.

[9] Rodolfo Abarca-Vargas and Vera L Petricevich. "Bougainvillea Genus: A Review on Phytochemistry, Pharmacology, and Toxicology". (2018) Article ID 9070927.

[10] Emery H. Bresnick, Kyle J. Hewitt, Charu Mehta, Sunduz Keles, Robert F. Paulson and Kirby D. Johnson Mechanisms of erythrocyte development and regeneration: implications for regenerative medicine and beyond development. (2018). doi: 10.1242/dev.151423

[11] Mehta Sonam, Rana Pawan Singh, Saklani Pooja. Phytochemical Screening and TLC Profiling of Various Extracts of Reinwardtia indica. IJPPR, Volume 9, Issue 4 (2017).

[12] Bikash Debnath, MD.Jashim Uddin, Prasenjit Patari, Manik Das, Debasish Maiti \& Kuntal Manna. Estimation of Alkaloids and Phenolics of five edible Cucurbitaceous plants and their 
antibacterial. IJPPS, ISSN- 0975 1491, Vol 7, Issue 12 (2015).

[13] V.L.Singleton \& J.A.Rossi. Colorimetry of total phenolics with phosphomolybdic - phosphotungstic acid reagents. Am J Enol Vitic, 16, (1965). pp.144-15

[14] Zhishen J, Mengcheng $T$ and Jianming $\mathrm{W}$. The determination of flavonoid contents in mulberry and their scavenging effects on superoxide radicals. Food Chemistry, 64, (1999). 555-559

[15] Sujima Anbu.A, Sahi SV and Venkatachalam P. "Synthesis of Bioactive Chemicals Cross-linked Sodium ripolyphosphate (TPP) Chitosan Nanoparticles for Enhanced Cytotoxic Activity against Human Ovarian Cancer cell Line (PA-1)" J Nanomed Nanotechnol, an open access journal. ISSN: 2157-7439.Volume 7, Issue 6, (2016) 1000418.

[16] Nathasa Weisdania Sihite, Herla Rusmarilin, Dwi Suryanto and Dewi Restuana Sihombing. Utilization of jasmine flower extract as antimicrobial in tempeh sausage. IOP Conf. Series: Earth and Environmental Science, IOP Publishing, (2018) doi: 10. 1088/ $1755-1315 / 205 / 1 / 012037$
[17] Rakam Gopi Krishna, Raja S. Standardization and phytochemical screening of Bougainvillea glabra. Int J Curr Pharm Res; 9(5): (2017) 75-80.

[18] Farah Haddouchi, Tarik Chaouche, Abdelhafid Benmansour and Hamadi Abder rahmane Lazouni. "Phytochemical study of Thymus fontanesii and Laurus nobilis".Der Pharmacia Lettre, 3(2): (2011) 343-350

[19] Shahidi F., Wanasundara PKJPD. Phenolic antioxidants. Critical Reviews in Food Science and Nutrition, Vol. 32, (1992), Page No. 67-103

[20] Soobrattee MA1, Neergheen VS, Luximon-Ramma A, Aruoma OI \& Bahorun T. Mutat Res; 579(12): (2005). 200-13.

[21] Zhou X, Ni P, Yu Z. Comparison of RAFT polymerization of methyl methacrylate in onventional emulsion and miniemulsion systems. Polymer 48: (2007). $6262-71$

[22] Tanvir Ahamed Peash, SK. Mizanur Rahman, Abdullah Mohammad Shohael. Thin layer chromatographic profiling and phytochemical screening of six medicinal plants in Bangladesh International Journal of 
Biosciences. (2017). DOI:

10.12692/IJB/11.1.131-140

[23] Mehta Sonam, Rana Pawan Singh, Saklani Pooja. Phytochemical Screening and TLC Profiling of Various Extracts of Reinwardtia indica. IJPPR, Volume 9, Issue 4. (2017).

[24] S. Vaezifar, M. A. Golozar, S. Razavi, S. Karbasi, M. Morshed and M. Kamali. Effects of some parameters on particle size distribution of Chitosan nanoparticles prepared by Ionic gelation method. $\mathbf{J}$ Clust Sci; 24: (2013). 891-903. DOI 10.1007/s10876-013-0583-2.

[25] AbdElhady MM. Preparation and characterization of Chitosan/Zinc oxide nanoparticles for imparting antimicrobial and UV protection to cotton fabric. Int $\mathrm{J}$ Carbohyd Chem. (2012). Article ID 840596

[26] Mohanty JG, Nagababu E and Rifkind JM Red blood cell oxidative stress impairs oxygen delivery and induces red blood cell aging. Frontiers in Physiology; 4(5) (2014): 1-6.

[27] Ko FN, Hsiao G, Kuo YH: Protection of oxidative hemolysis by demethyl di iso eugenol in normal and $\beta$-thalassemic red blood cells. Free RadicBiol Med; 22: (1997). 215-222

[28] Oyedemi SO and Afolayan A J. Antibacterial and antioxidant activities of hydroalcoholic stem bark extract of Schotia latifolia Jacq. Asian Pac J Trop Med; 4(12): (2011). 952-958

[29] Varun Tyagi, Ranjeet Patel, Hemanga Hazarika, Piyali Dey, Diganta Goswami and P Chattopadhyay "Chemical composition and bioefficacy for larvicidal and pupicidal activity of essential oils against two mosquito species". International journal of mosquito research, (2017). 112-118. 